\title{
Peripheral Neuropathy in Allergic Granulomatous Angiitis
}

\author{
TETSUKO OKUNO, MASASHI SAGARA*, AKIO INOUE** \\ AND MITSUYOSHI AYABE ${ }^{\dagger}$ \\ Department of Orthopaedic Surgery, Yanagawa Rehabilitation Hospital, \\ Yanagawa 832, *Department of Orthopaedic Surgery, Kurume University \\ Medical Center, Kurume 839 and Departments of Orthopaedic Surgery** \\ and Medicine ${ }^{\dagger}$, Kurume University School of Medicine, Kurume 830, Japan
}

\section{Received for publication May 2, 1997}

\begin{abstract}
Summary: A 61-year-old woman began to suffer bronchial asthma in 1985. She then developed low back pain and numbness along the lower extremities, eventually leading to bilateral drop foot in 1990. At that time, she was diagnosed as having lumbar disc hernia, and extirpation of the discs at the L3-4 and L4-5 was performed. However, her clinical condition showed little improvement. Six months later, she was emaciated and bedridden with distal dominant muscular atrophy in all four limbs, purpura in the left leg and hypereosinophils. Motor conduction velocity (MCV) was not detected in the peroneal nerves. The toes gradually became cyanotic, and a skin biopsy from the cyanotic region revealed necrosis in the vessels surrounded by infiltration of a large number of neutrocytes and lymphocytes. She was diagnosed as having mononeuritis multiplex due to allergic granulomatous angiitis (AGA), which is characterized by bronchial asthma, hypereosinophilia and necrotizing vasculitis. Thirty $\mathrm{mg}$ /day prednisolone was then administered. However, the toes and calcaneal areas gradually became necrosed. Finally, amputation of both feet was necessary. We concluded that an early diagnosis of this syndrome is most important, and corticosteroids should be administered early.
\end{abstract}

Key words allergic granulomatous angiitis, Churg-Strauss syndrome, mononeuritis multiplex, peripheral neuropathy, drop foot

\section{Introduction}

Allergic granulomatous angiitis or Churg-Strauss syndrome is a diffuse systemic vasculitis characterized by bronchial asthma, hypereosinophilia and necrotizing vasculitis which is sometimes fatal. The manifestations of vasculitis are frequently mononeuritis multiplex, cutaneous signs and gastrointestinal tract involvement. However, in most cases mononeuritis multiplex itself is manifested as peripheral neuropathy accompanying other significant organ involvement.

Here, we describe a patient with a history of bronchial asthma, who manifested mononeuritis multiplex with bilateral drop foot and atrophy in the fingers. In the final necrotic stages, the patient was diagnosed as having an allergic granulomatous angiitis, and should have received amputation of both necrotic feet. 
We emphasize that an early recognition of this syndrome is most important and corticosteroids should be administered in the early stages as far as possible.

\section{Case Report}

The patient was a 61-year-old female who had suffered from asthma since 1985. She was admitted to the hospital for two weeks in April 1990 because of a severe attack of bronchial asthma. Since then, low back pain with numbness along the lateral regions of the left leg to foot gradually developed weakness of both feet, leading to bilateral drop foot. She was then referred to the Department of Orthopaedic Surgery of Kurume University Hospital, at the end of August 1990.

On examination she complained of diffuse articular pain in both lower limbs, and numbness in the left lower extremity suggesting sciatica. There was hypesthesia and paresthesia below the knees with paralysis in the $\mathrm{N}$. peroneus profundus completely on the left side, and incompletely on the right side. A manual muscle testing revealed the tibialis anterior grade $0 / 5$ weakness on the left side and $2 / 5$ on the right side. The straight leg raising test was negative bilaterally. There was no tenderness in the low back region.

In laboratory findings, the white cell count was $10500 / \mathrm{mm}^{3}$ with $76 \%$ eosinophils, the erythrocyte sedimentation rate was $59 \mathrm{~mm}$ per hour. A myelogram of the lumbar spine revealed herniated discs at L3-4 and L4-5 without any other abnormalities, and magnetic resonance images revealed similar findings.

Laminectomy and extirpation of the herniated disc at the level of L3-4 and L4-5 were performed in October 1990. However, she complained of numbness in both legs and feet. She began to notice numbness and muscular atrophy in her right hand in February 1991. This was ascribed to cubital tunnel syndrome and neurolysis was then performed by an orthopaedic practitioner.

However, she soon noticed her left small finger could not adduct; also she felt fatigue; and extreme limb weakness so that she could walk only with severe difficulty. She was at that time referred to the First Department of Internal Medicine of Kurume University Hospital with suspected polyneulitis.

On examination she was emaciated and bedridden. Her height was $147 \mathrm{~cm}$ and weight $32 \mathrm{~kg}$. The clinical findings were (1) bronchial asthma that preceded the developmental symptoms, (2) some eruptions like purpura seen in the lateral side of the left leg. However, A. dorsalis pedis was palpable bilaterally, and (3) muscular atrophy and weakness in both upper and lower extremities with distal dominant distribution. The patellar and Achilles tendon reflexes were negative bilaterally. The grip strength was $0.5 \mathrm{~kg}$ on the right side, and $6 \mathrm{~kg}$ on the left side.

The laboratory findings were the white cell count of $10000 / \mathrm{mm}^{3}$ with $38 \%$ eosinophils; ESR $22 \mathrm{~mm}$ per hour; $1 \mathrm{gE}$ $373 \mathrm{mg} / \mathrm{dl}$; RAPA $640 \mathrm{mg} / \mathrm{dl}$.

No motor conduction velocity (MCV) was found in the right median nerve, left ulnar nerve and both peroneal nerves. The left median nerve MCV was 48.9 
$\mathrm{m} / \mathrm{sec}$, and the right ulnar nerve MCV was $51.5 \mathrm{~m} / \mathrm{sec}$. The sensory action potentials for sural nerves showed no response. Three weeks after admission, on May 27, both toes became cyanotic and she was administered prostaglandin E. However, the cyanosis progressed to the lateral region of the left leg.

A skin biopsy was performed from the lateral side of the left leg, at approximately 14 months after the onset of neuropathy. The result showed necrosis in the vessels, and the elastic lamina was disrupted and surrounded by infiltration of a large number of neutrocytes and lymphocytes in the perivascular tissues (Fig. 1). There were small numbers of eosinophils in few regions of tissue (Fig. 2).

Diagnosis of AGA was made clini- cally and pathologically, $30 \mathrm{mg}$ of prednisolone per day was administered from June 6 , however, the ischemic areas had by then developed into both legs and the right first to third toes were necrosed (Fig. 3). The amount of prednisolone was gradually decreased within about a two-month period to $10 \mathrm{mg}$ of prednisolone because of gastritis. On September 19, 1991, the necrosed region spread to the right Achilles tendon area and both calcaneal areas, requiring amputation below the knee on the right side and at the Chopart's joint on the left side.

Gait training finally allowed the patient to start wearing a bilateral prosthesis since April 1992. During this time she was given $5 \mathrm{mg}$ of prednisolone. However, she frequently suffered from

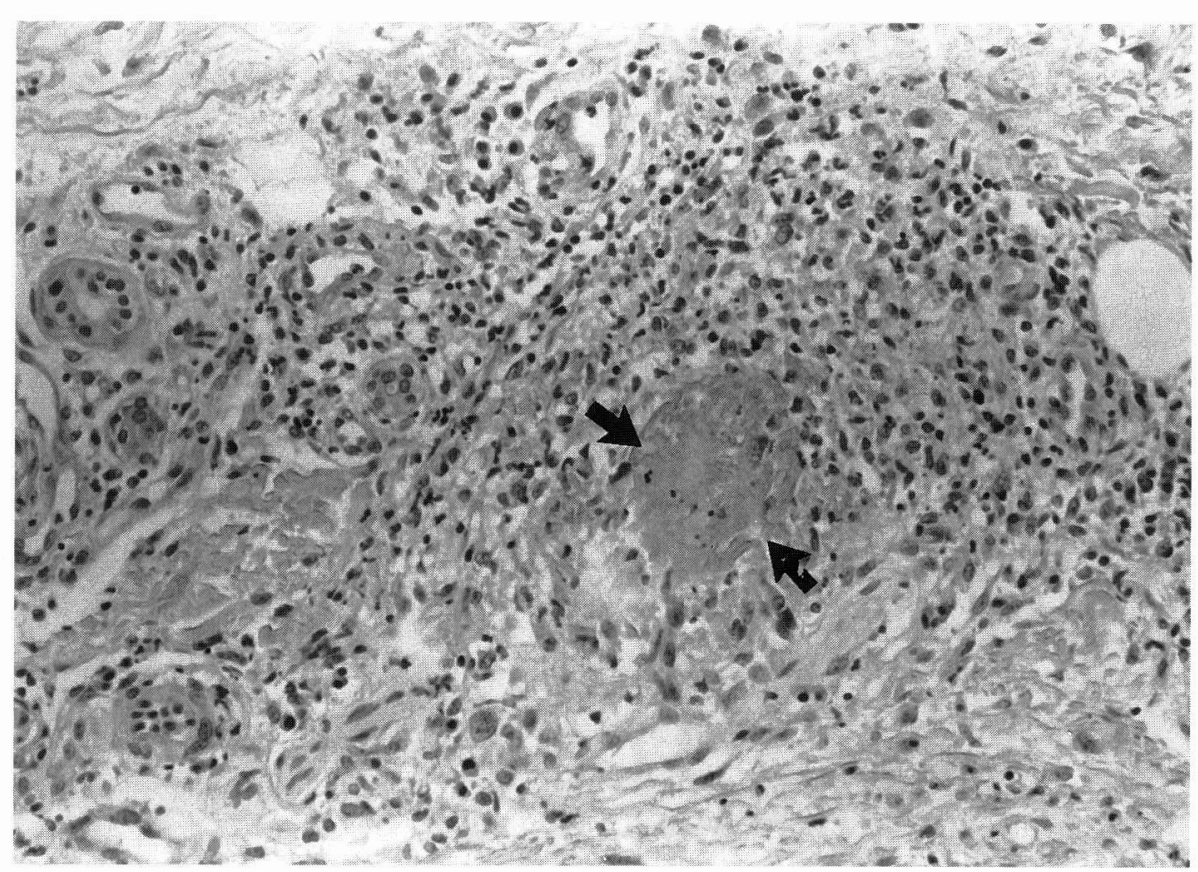

Fig. 1. Photomicrograph of the necrotic skin showing necrosis of the vessels surrounded by infiltration of neutrocytes and lymphocytes. 


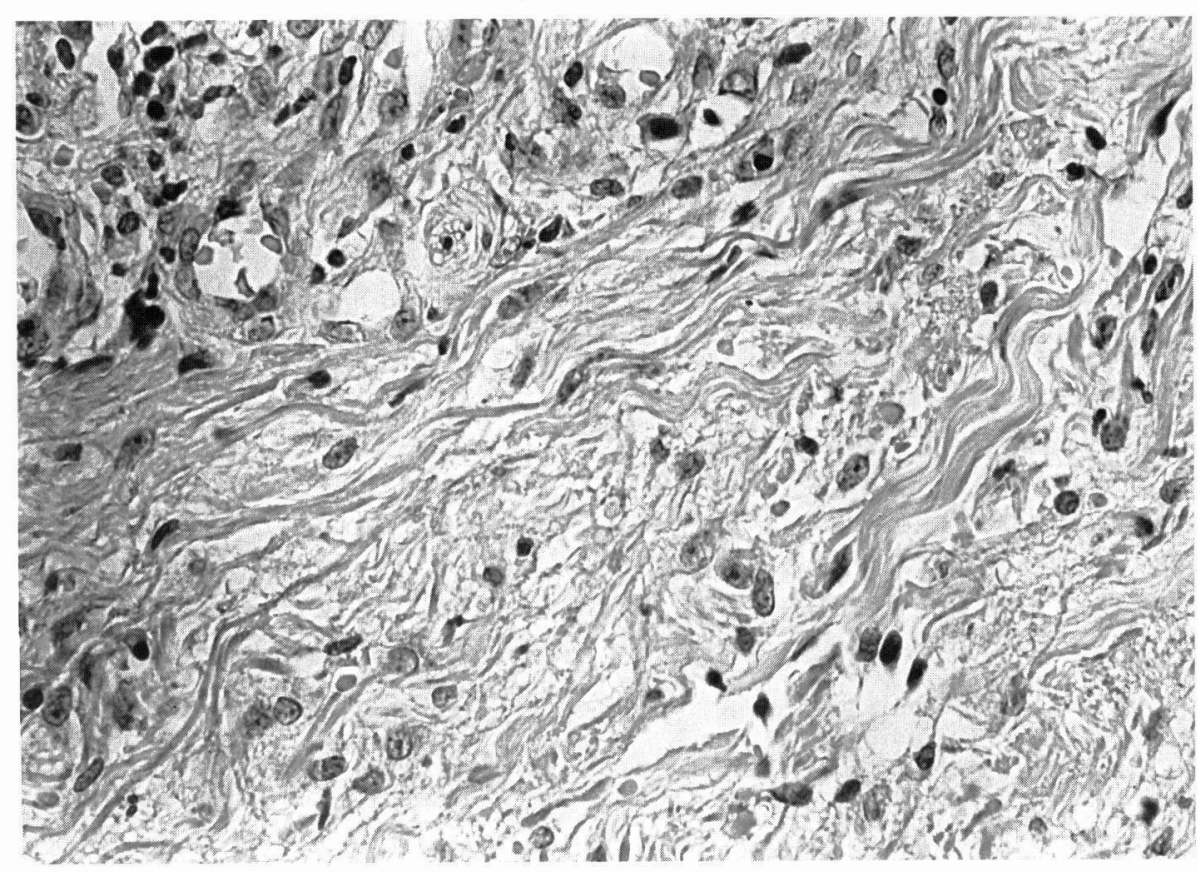

Fig. 2. Photomicrograph of the same skin showing a very small number of eosinophils in a few regions only.

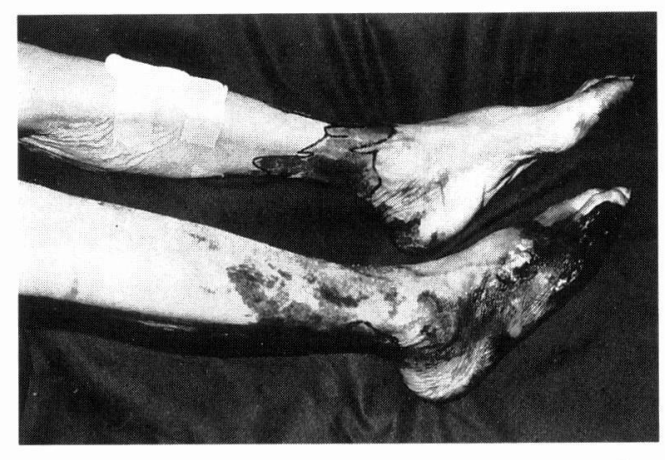

Fig. 3. Photograph of the lower limbs showing ischemic region on the right distal leg with necrosis of the right 3 to 5 toes, and on the middle to distal part of the left leg.

attacks of bronchial asthma, and suffered a cardiac failure at the end of December 1992.

Exercise was resumed in June 1993, she could walk wearing a PTB prosthesis on the left side and a Japanese socks-type prosthesis on the right side with two Lofstrand crutches at 4 months after starting exercise.

The $5 \mathrm{mg}$ prednisolone was maintained and the colour of both stumps was good with no signs of vascular angiitis. No attack of brochial asthma occurred after May 1993. On muscle testing, the muscle strength of the lower extremities was $4 / 5$ or $5 / 5$ grade level, and the grip strength was $12 \mathrm{~kg}$ on the right side and $11 \mathrm{~kg}$ on the left side.

\section{Discussion}

Allergic granulomatous angiitis (AGA) or Churg-Strauss syndrome was first distinguished from periarteritis 
nodosa by Churg and Strauss in 1951 . AGA was then characterized as a severe illness involving multiple organ systems associated with pathologically necrotizing vasculitis with extravascular granuloma and tissue infiltration by eosinophils. The syndrome has often progressed insidiously and unrecognized, and sometimes becomes fatal.

There have been 54 case reports in Japan during the two years from January 1993 (Shibata et al.) to December 1994 (Katsuki et al.), involving 22 men and 32 women, whose ages ranged from 13 to 77 years, averaging 45 years (excluding one case of 4-year-old boy who did not suffer from bronchial asthma (Hatakeyama et al. 1994)). The mean duration of asthma prior to onset of vasculitis was 3.3 years in the series of 11 cases reported by Hayakawa et al. in 1993. Heart failure, myocardial infarction and cerebral hemorrhage were the three major causes of death in 7 cases that were fatal.

Mononeuritis multiplex in peripheral spinal nerves manifesting as the main clinical sign in two (Sameda et al. 1993; Tsuda et al. 1994) of the 54 cases, and one (Sameda et al. 1993) of these had a drop foot.

A neurological disorder is usually the cause of mononeuritis multiplex (Chumbley et al. 1977; Lanham et al. 1984; Sehgel et al. 1995) which frequently develops in the peripheral spinal nerves (Lanham et al. 1984). Sensory disturbance then occurs in the sural nerve in the early stages. Inoue et al. (1992) have analysed 8 cases with peripheral nerve involvement. Six of these 8 cases had a sensory disturbance in the sural nerve region. In 7 of these 8 cases, a sural nerve biopsy showed infiltration by mononuclear cells into the endoneurium and perineurium, with granulomatous lesions in the perineurium, but no eosinophils. Kawai et al. (1977) have reported that a left ulnar nerve lesion in the axilla, due to AGA, was misdiagnosed as a tumor of the ulnar nerve in the epineurium. During resection, numerous yellow granules 1-2 mm in diameter were seen on the epineurium.

Drop foot and weakness in the foot usually develops in the later stages due to the peroneal nerve involvement, and has been described by several authors (Dorfman et al. 1983; Cavallaro et al. 1988; Engelhardt et al. 1989; Marazzi et al. 1992; Scully et al. 1992; Sameda et al. 1993). Cavallaro et al. (1988) described a sural nerve biopsy in the late stage involving drop foot, which found an almost complete disappearance of myelinated fibers and an involvement of unmyelinated fibers. A skin biopsy showed small granuloma with histiocytic infiltration. In our case, a skin biopsy was conducted during the late chronic necrotizing stage, and showed necrosis and disruption of the vessels with infiltration of neutrocytes and lymphocytes into adjacent tissue.

In the early stages, AGA responds well steroid treatment. Patients presenting drop foot treated with 40-to-60 mg prednisolone or prednisone per day generally show improvement or stabilization (Dorfman et al. 1983; Marazzi et al. 1992; Sameda et al. 1993). According to the guidelines for AGA advocated by the Ministry of Health and Welfare in Japan (Yoshida, 1992), the initial dosage of 20 -to- $80 \mathrm{mg}$ prednisolone should be maintained for 2 to 4 weeks, and then 
decreased by $10 \%$ every 2 or 3 weeks thereafter, depending on the observed clinical findings. Maintenance is kept below $10 \mathrm{mg}$ prednisolone until full recovery, when it is stopped. However, the dosage required initially and the improvements required for reducing this dosage are not all clear for peripheral nerve involvement. In large parts this is due to the clinical differences among the cases.

Marrazi et al. (1992) described that in one of three cases, neuropathy in the lower limbs and other signs and symptoms vanished within 10 days of treatment with $50 \mathrm{mg}$ prednisone, but that $50 \mathrm{mg}$ steroid therapy was withdrawn after 60 days because of hemorrhaging gastritis. All symptoms and signs reappeared one month later. Three months later, the patient was unable to walk without support. In our case, the reduction of steroid therapy led to the recurrence of bronchial asthma and subsequently to heart failure.

Engelhardt et al. (1989) reported that in one case of drop foot, $80 \mathrm{mg}$ prednisolone and $100 \mathrm{mg}$ azathiopirine was administered, and the amount of prednisolone was decreased slowly down to $12 \mathrm{mg}$ by controlling erythrocyte sedimentation rate (ESR). This $12 \mathrm{mg}$ was maintained and the patient's general condition improved, with only slight paresis remaining at one year and 10 months after beginning of the treatment. However, marked osteoporosis in the spinal column with pain occurred at 2 years of steroid therapy.

Peripheral neuropathy showed gradual improvement, and the patient eventually recovered to be able to walk independently in one of Dorfman's (1983) case, but in most cases weakness in the lower limbs or drop foot has persisted. The results depend on the follow up period, but in most cases, in severe neuropathy of the late stage, complete recovery from muscle weakness is difficult.

Our case was not successful with steroid therapy because diagnosis was too late and there was insufficient administration of steroid. If the patient was diagnosed as AGA in the early stage, at onset of drop foot, and had been given a higher dosage of steroid then she might have been able to recover the ability to walk with or without wearing a brace.

\section{References}

Cavallaro T, Tenze F, Lazzarino LG, Nicolai A, Rizzuto $\mathrm{N}$ et al. Peripheral neuropathy associated with allergic granulomatous angiitis (Churg-Strauss syndrome): clinical features and histological findings. Ital $\mathrm{J}$ Neurol Sci 1988; 9:595-598.

Chumbley LC, Harrison EG, and DeRemee RA. Allergic granulomatosis and angiitis (ChurgStrauss syndrome) report and analysis of 30 cases. Mayo Clin Proc 1977; 52:477-484.

Churg J, and Struss L. Allegic granulomatosis, allergic angiitis, and periarteritis nodosa. Am J Pathol 1951; 27:277-301.

Dorfman LJ, Ranson BR, Forno LS, and Kelts A. Neuropathy in the hypereosinophilic syndrome. Muscle \& Nerve 1983; 6:291-298.

Engelhardt A, Thron C, Glotzner FL, and Neundorfer B. Polyneuropathie bei ChurgStruss-Syndrom. Dtsch Med Wschr 1989; 14:911-913.

Hatakeyama K, Amamiya S, Sawanobori E, Higashida K, Matsui T et al. A 4 year-old boy with polyangiitis overlap syndrome -the peculiarity of clinical aspects due to his young age-. Nippon Shonika Gakkai Zasshi 
(J J P S) 1994; 98:1418-1423. (in Japanese)

Hayakawa H, Sato A, Yagi T, Shimizu T, Miyajima $\mathrm{H}$ et al. Clinical features and prognosis of Churg-Strauss syndrome. Nippon Kyobu Sikkan Gakkai Zasshi (J J T D) 1993; 31:59-64. (in Japanese)

Inoue A, Koh C-S, Tsukada N, and Yanagisawa $\mathrm{N}$. Allergic granulomatous angiitis and peripheral nerve lesion. Intern Med 1992; 31:989-993.

Katsuki A, Taguchi O, Yamagami T, Ibata H, Gabazza $\mathrm{E}$ et al. A case of allergic granulomatous angiitis with von Meyenburg complex of the liver. Nippon Kyobu Rinsho (J P N J) 1994; 53:1019-1023. (in Japanese)

Kawai K, Kumazawa S, and Suzuki N. A case of the ulnar nerve lesion due to allergic granulomatous angiitis. Chubu Seisai Shi (Cent Jpn J Orthop Traumat) 1977; 20:188190. (in Japanese)

Lanham JG, Elkon KB, Pusey CD, and Hughes GR. Systemic vasculitis with asthma and eosinophilia: a clinical approach to the Churg-Strauss syndrome. Medicine 1984; 63:65-81.

Marazzi R, Pareyson D, Boiardi A, Carbo M, Scaioli V et al. Peripheral nerve involvement in Churg-Strauss syndrome. J Neurol 1992; 298:317-321.

Sameda H, Matsubara T, Tsuburai Y, Masuda S, Hirano $S$ et al. A case report of allergic granulomatous angiitis. Seikeigeka (Orthopaedic Surgery) 1993; 44:1518-1519. (in Japanese)

Scully RE, Editor. Case records of the Massachusetts General Hospital, weekly clinicopathological exercise. N Eng J Med 1992; 326:1204-1212.

Sehgel M, Swanson JW, DeRemee RA, and Colby TV. Neurologic manifestations of Churg-Strauss syndrome. Mayo Clin Proc 1995; 70:337-341.

Shibata T, Perparim K, Sumie A, Ishii T, Tomo T et al. A case report of allergic granulomatous angiitis (Churg-Strauss syndrome) with a review of the literature. Japanese $\mathbf{J}$ Nephrology 1993; 35:83-88.

Tsuda M, Kodera T, Kikuchi M, Nomura T, Kobayashi $\mathrm{K}$ et al. A case of allergic granulomatous angiitis. Yamagata Saiseikan Ishi 1994; 19:136-141. (in Japanese)

Yoshida M. Allergic granulomatous angiitis (Churg-Strauss syndrome). Ryumatika (Rheumatology) 1992; 8:167-173. (in Japanese) 